and Gendrin, who, while fully recognising the precision of diagnosis to be often derived from the use of the speculum uteri, only admitted its value as supplemental to a digital examination, of which they always recognised the paramount importance. I have no hesitation in affirming that all subsequent writers of any eminence on diseases of women have taught the same lesson either by example or by actual precept; and I only claim to have made myself the intelligent echo of those who have preceded me, when I stated in my Handbook of Uterine Therapeutics, "that no other mode of examination gives so many valuable elements of diagnosis as a digital examination, that it is often the only one required, and the only one that is not fraught with danger."

A little further on, in the same lecture, Dr. Graily Hewitt leads his pupils to believe that the extreme importance of a digital examination has at least been recognised in a recent work by Dr. Courty.

I do not know how far my friend Dr. Courty will like being singled out for praise, equally well deserved by so many of his predecessors and contemporaries; but I beg to enter my protest against Dr. Graily Hewitt's mode of writing history for the pupils of University College.

I am, Sir, yours obediently,

Grosvenor-street, May 24th, 1871.

Edward J. TILT.

\section{THE DEFECT OF HEARING IN DIPHTHERIAL PARALYSIS.}

To the Editor of THE LANCET.

Srn,-In reply to the questions asked by Dr. Hughlings Jackson in your last impression, I write to give a brief statement of the case in which this occurred. Mrs. W. resided in a house the drainage of which was admittedly bad, and had been ailing for several days before I saw her. She then complained of great weakness and slight fever. The throat was red and inflamed, and she thought this was caused by exposure to damp some days previously. On the second day after I saw her the characteristic exudation appeared, and at the same visit $I$ observed slight deafness. On the next day this had much increased, and there was great dificulty in deglutition. In twenty-four hours the paralysis was complete, so that she could swallow nothing. The muscles of the larynx were also affected, as she could not speak. The paralysis gradually extended to the muscles of respiration, and I think the muscles of the eye were also affected. I judge so from the appearance of the eye and the permanently dilated pupil. The usual remedies were used, but the patient sank, starved to death, in six days. The defect in hearing was not slight; she did not hear except when spoken to in the loudest pitch of voice, and, as she could not speak, nodded a reply. I am, Sir, yours faithfully,

May 29th, 1871. JaMns THompson, M.D.

\section{VACCINATION FROM THE HEIFER.}

\section{To the Editor of THE LANCET.}

SiR,-In the present discussion on vaccination, the following cases of revaccination, direct from the calf, performed on a family of twelve persons, appear to me to bear a certain amount of interest as regards complications that may arise even under such circumstances.

In six the ages varied from nine to twenty years; of these, three had enlargement of the glands in the axilla five healed in three, and one in four weeks. In the remaining six, the age was from twenty upwards; of these three suffered considerably from tenderness in the axilla, with an inflammatory condition of the entire arm on its outer surface, down to and slightly below the elbow, the ulcers having healed respectively in iourteen, seventeen, and thirty-three days. In the last a papular exuption appeared on the arm before, and did not disappear until a short time subsequent to, its healing. In the remaining three there was enlargement of the glands in the axilla; the ulcers healing, two in seven, and one in eight weeks. In two the ulcer was elevated, with a thickened base; the third somewhat excavated, with an irregular bleeding surface, sharp, well- defined edges and thickened base, followed by a small abscess below the clavicle.

The only treatment employed was bread-and-milk poultice for a couple of nights, and subsequently water dressing.

The vaccination was performed in each case at three points on the outside of the left arm over the deltoid, all of which were successful, except in three of the youngest, in which one point failed in each. All the above have continued in grood health since their local troubles terminated. I remain, Sir, your obedient servant,

May $27 \mathrm{th}, 1871$. JoHN W. TROTTER, Coldstream Guards.

\section{THE LATE INQUEST AT CHURCH.}

To the Editor of THE LANCET.

Sir,-I see in your issue of Saturday, the 27th inst., my name brought prominently before the medical public.

I am very sorry that your informant has not been able to state more correctly the real facts as regards the late policesergeant of Church. So far as my calling on the patient unasked is concerned, it is utterly false. Neither can I express too strongly my disapprobation of any medical man's interfering with another's patients, and the only part I played in that affair was simply this :-The wife came running down to my surgery on Wednesday evening abutut seven o'clock, being their regular attendant, residing only a few yards from their house (Mr. Martland a distance of at least four miles), and begged I would go at once to see her husband, as she was afraid he was dying. Seeing the woman's distress, could I do less than go? or, would it have been more humane to have added one drop more of bitterness to the woman's cup of sorrow by telling her to send for Mr. Martland, as I understood he was the surgeon for the police-force? I think that the least that could be done was to go at once, and, if only by a word of sympathy, to calm her already over-wrought feelings. Such was what I did, and this was my only visit. As to the "digitalis and other powerful remedies," alas! there was no need for them; he was then sinking into a state of coma, and unable to swallow anything, from which he never rallied.

I am more than astonished that any gentlemain cannot be a little more careful in publishing things hurtful to another's feelings, without mistaking names, addresses, and dates. Semper fari quod verum est, is a motto which your correspondent would do well to learn.

Trusting that you will give this as prominent a place in your paper as you did the other,

I am, Sir, yours, \&c.,

Brook House, Church, May 30th, $1871 . \quad J$ Joh DeARDEN.

\section{BIRMINGHAM.}

(FROM OUR OWN CORRESPONDENT.)

THE projected special hospital for the diseases of women has advanced several stages during the last few weeks. The subscribers have taken a house, No. 8 , Crescent, at an estimated rental of $\$ 40$ per annum, and have already decided who are to be on the consulting staff and who are to be the managing committee. A peculiar feature about the latter body is, that of eighteen members, nine are of the fair sex, a decided innovation in hospital management, the value of which remains to be seen. The consulting physicians are Dr. Bell Fletcher and Dr. Fleming, and the consulting surgeons Messrs. Berry and Furneaux Jordan, all men of eminence, whose names will give strength to the institution; but the real work of the hospital is to be done by four acting surgeons, who will be elected by a special committee to be appointed for the purpose, consisting of twenty governors selected by ballot from the general body of subscribers, together with the honorary and consulting stafi. Numerous candidates are in the field, and amongst them many rising surgeons of note. Some of the rules of this institution are peculiar. One restriets the period of 